\title{
LA PROGRESIVIDAD EN LA JURISPRUDENCIA DE LA CORTE INTERAMERICANA DE DERECHOS Humanos
}

\author{
Liliana Galdámez ZeladA*
}

RESUMEN: El trabajo aborda el carácter progresivo del Derecho Internacional de los Derechos Humanos y su impacto en la Jurisprudencia de la Corte IDH. La progresividad implica el desarrollo constante y permanente del Derecho Internacional de los Derechos Humanos, una suerte de derecho mínimo e irreversible, que solo admite avances y mejoras, nunca una vuelta atrás. Esta actividad constante se traduce en la práctica en el mejoramiento de los estándares de protección a través de la actividad jurisprudencial de los tribunales internacionales de derechos bumanos. Se propone analizar el contenido y alcance de la progresividad y algunos criterios elaborados por la Corte IDH a partir de este carácter.

Palabras Clave: Progresividad - Derecho Internacional de los Derechos Humanos - Corte Interamericana de Derechos Humanos Estándar de protección de los derechos humanos.

\section{Progressiveness in the Jurisprudence of THE INTER- American Court of Human Rights}

ABSTRACT: This paper examines the progressiveness principle of the International Law of Human Rights and its impact in the Jurisprudence of the Inter-American Court of Human Rights. Progressiveness implies the constant and permanent development of International Law of Human Rights, some sort of minimum and irreversible right that only allows improvements, and never a returning point. This constant activity is translated to the improvement of the protection standards through the study of Law of the international courts of buman rights. Its aim is to analyze the content and scope of progressiveness and some criteria elaborated by the Inter-American Court of Human Rights starting from this feature.

Abogada, consultora en la Oficina Regional para América Latina del Alto Comisionado de las Naciones Unidas para los Derechos Humanos. Candidata a doctora por la Universidad de Valladolid (España).Correo electrónico: lilianaandrea.galdamez@ alumnos.uva.es

Fecha de recepción: 28 de junio de 2007.

Fecha de aprobación: 10 de marzo de 2008. 
KEY wORDS: Progressiveness - International Law of Human Rights - Inter-American Court of Human Rights - Protection of human rights standard.

SUMARIO: Introducción I. Definición y caracteres del Derecho Internacional de los Derechos Humanos II. La progresividad III. La progresividad en la jurisprudencia de la Corte Interamericana de Derechos Humanos. Conclusiones.

\section{INTRODUCCIÓN}

Uno de los desarrollos más importantes y destacados del Derecho latinoamericano es el que se observa en el ámbito del Derecho Internacional de los Derechos Humanos ${ }^{1}$. Aunque el acelerado desarrollo del DIDH no es homogéneo, es progresivo, lo que se expresa en: el creciente desarrollo y permanente elaboración de instrumentos internacionales de protección; la regular creación de organismos especializados en verificar el cumplimiento de los compromisos asumidos en los tratados; la instauración de tribunales internacionales para perseguir responsabilidades en el ámbito estatal y penal; y, en la formulación de criterios elaborados por la jurisprudencia de los tribunales internacionales de derechos humanos. Todos estos progresos han incidido favorablemente para que se consoliden criterios básicos, ahora incuestionables, como la no prescriptibilidad, amnistía, ni eximentes de la responsabilidad penal a los crímenes más graves contra los derechos humanos. Asimismo, la aceptación de estos criterios en el ámbito del derecho interno, ha permitido una mayor y mejor protección a los derechos humanos, avance que deriva del carácter progresivo de esta rama del Derecho Internacional ${ }^{2}$.

Así se desprende la sentencia de 13 de marzo de 2007 dictada por la Segunda Sala Penal de la Corte Suprema, rol 3125-04: "DÉCIMO SEXTO: Que, por consiguiente, resultan plenamente aplicables al bomicidio cometido en la persona de Manuel Tomás Rojas Fuentes, los Convenios de Ginebra de mil novecientos cuarenta y nueve, antes aludidos, que en su artículo $3^{\circ}$ común a todos ellos, obliga a los Estados contratantes, en caso de conflicto armado sin carácter internacional ocurrido en su territorio, al trato bumanitario de las personas que no participen directamente en las hostilidades, incluso los miembros de las Fuerzas Armadas que hayan depuesto sus armas y aquellos que ban quedado fuera de combate por enfermedad, herido, detención o por cualquiera otra causa, sin distinción alguna de carácter desfavorable, probibiéndose para cualquier tiempo y lugar: "a) los atentados a la vida y a la integridad corporal, especialmente el homicidio en toda sus formas, las mutilaciones, los tratos crueles, torturas y suplicios; b) la toma de rehenes; c) los atentados a la dignidad personal, especialmente los tratos bumillantes y degradantes; d) las condenas dictadas y las ejecuciones efectuadas sin previo juicio, emitido por un

En adelante DIDH

En adelante DI. 
tribunal regularmente constituido, provisto de garantias judiciales reconocidas como indispensables por los pueblos civilizados".

Asimismo, ese Instrumento Internacional consigna en su artículo 146 el compromiso de sus suscriptores para tomar todas las medidas legislativas necesarias en orden a fijar las adecuadas sanciones penales que hayan de aplicarse a las personas que cometen, o den orden de cometer, cualquiera de las contravenciones graves definidas en el Convenio; como también se obligan los Estados a buscar a tales personas, debiendo hacerlos comparecer ante sus propios tribunales y a tomar las medidas necesarias para que cesen los actos contrarios a las disposiciones del Acuerdo. Precisa que en toda circunstancia, los inculpados gozarán de las garantías de un justo procedimiento y de libre defensa que no podrán ser inferiores a los previstos en los artículos 105 y siguientes del Convenio de Ginebra, de doce de agosto de mil novecientos cuarenta y nueve, relativo al trato de los prisioneros de guerra. Y en el artículo 147 describe lo que se entiende por infracciones graves, a saber, entre ellos, el homicidio intencional, torturas o tratos inbumanos, atentar gravemente a la integridad física o a la salud, las deportaciones, traslados ilegales y la detención ilegítima.

...DÉCIMO OCTAVO: Que la mentada probibición de autoexoneración no dice relación solo con las consecuencias civiles de las transgresiones verificadas, sino también, y de manera primordial, a las sanciones penales contempladas para ellos, pues es claro que, respecto de bechos de esta clase, cobra una importancia fundamental la función de prevención general de las reacciones punitivas, la cual exige que las amenazas contenidas en las normas correspondientes se hagan efectivas en cualquier momento en que la persecución de los responsables se haga posible y aunque la de prevención especial parezca ya satisfecha porque el transcurso del tiempo haya convertido a los infractores en ciudadanos inofensivos. La sociedad, en efecto, no toleraría que violaciones de tal magnitud queden definitivamente impunes, con el pretexto de que el castigo ya no puede resocializar al que no está más en condiciones de reincidir pues, no obstante ello, si puede actuar reforzando para el futuro en los ciudadanos el respeto por los valores elementales sobre los que descansa la posibilidad de una convivencia pacifica (prevención general positiva) y disuadiendo a quienes se sientan inclinados a incurrir en bechos semejantes (prevención general negativa). Más aún cuando, "frente a la negación que el delito representa de los valores consagrados por una comunidad y a cuya preservación considera ésta ligadas su razón de ser y su organización y acción política y jurídica, el Derecho Penal los reafirma mediante la reprobación y el reproche de los actos que los niegan, expresando y concretando tal reafirmación en su punición, es decir, denotando de manera simbólica con ella la permanencia, en la sociedad, de sus aspiraciones valorativas y sus ideales de vida" (Manuel de Rivacoba y Rivacoba: "La Retribución Penal", Editorial Jurídica ConoSur Ltda., Santiago, Chile, año mil novecientos noventa y cinco, página 63).

Seguramente los Convenios de Ginebra asi lo tenían presente cuando establecieron la probibición examinada... Entonces se colige que no puede ser utilizada la amnistía en casos de delitos de guerra ejecutados al amparo del ejercicio de un poder incontrolado por agentes oficiales $u$ oficiosos del Estado, los que se encuentran severamente reprimidos en el ordenamiento jurídico nacional o internacional al momento de cometerse, utilizando la ley nacional como instrumento de incumplimiento y violación de tratados internacionales vigentes $y$ de principios generales de derecho de las naciones civilizadas, lo que impide usarla a la 
luz de la obligación de aplicar preferentemente los acuerdos y los cánones constitucionales de derechos bumanos sobre las normas de jerarquía legal en el ejercicio del poder que contradicen la obligación de respeto y promoción de los atributos esenciales, ya incorporados al ordenamiento jurídico nacional al momento de conocer y juzgar los bechos por sus órganos jurisdiccionales. Ello debido que, al primar los derechos contenidos en los tratados respecto de la ley de amnistía, esta última pierde aplicabilidad, por la mayor fuerza y resistencia de los Convenios de Ginebra que son de preferente de aplicación. De igual forma el Comité Internacional de la Cruz Roja ba expresado que no puede interpretarse en el sentido de apoyar amnistías "que vulneran el derecho bumanitario, sino que ellas deben posibilitar al término del conflicto la liberación de quienes fueron detenidos o sancionados por el simple becho de baber participado en ellas, no para aquellos que han vulnerado el derecho internacional bumanitario" (Informe $N^{\circ} 1 / 99$, Lucio Parada Cea y otros, El Salvador, veintisiete de enero de mil novecientos noventa y nueve, párrafos 114 y 115 )"3.

Apenas 11 años han trascurrido entre esta sentencia y la que citaremos a continuación: Corte Suprema de Chile, sentencia de 22 de agosto de 1996, $\mathrm{N}^{\circ}$ 2.277-96 por el homicidio de Carmelo Soria: "4. Que, de acuerdo con lo que previene el $\mathrm{N}^{\circ} 3$ del art. 93 del Código Penal, la amnistía es uno de los motivos de extinción de la responsabilidad penal y, según lo previsto en la Comisión Redactora del referido Código, deja al autor del delito ( $y$ con mayor razón a los cómplices y encubridores) en la misma situación en que estarían si no lo bubiere cometido... 14. Que también babría que agregar que al aplicar en este caso, el Decreto Ley $N^{\circ} 2191$ de 1978 , no se están vulnerando otros tratados internacionales sobre derechos bumanos, puesto que ellos son de vigencia posterior a la del Decreto Ley porque éste no ha impedido que se realice la más exhaustiva investigación posible sobre los hechos que culminaron con la muerte del señor Soria. Por estos fundamentos... se declara que se sobresee total y definitivamente en esta causa..."4

El desarrollo del DIDH puede comprenderse a partir de su carácter progresivo y, más concretamente, desde que se ha unido a la vertiente del constitucionalismo a través de cláusulas de apertura constitucional, ciertos derechos elaborados desde el DIDH, son admitidos como un límite a los poderes públicos de la misma manera que los derechos constitucionales, así se desprende de la sentencia que hemos mencionado en la primera parte.

Como señalamos, el reconocimiento del DIDH en el ámbito interno no es homogéneo, pues su validez es asumida con diversas fórmulas, según el país que analicemos 5 . En algunos casos la apertura constitucional ha derivado en que sea

Sentencia rol 3125-04, Segunda Sala Penal, Corte Suprema.

Sentencia de la Corte Suprema de Chile de 22 de agosto de 1996, N².277-96.

En clave hermenéutica, siguiendo el 10.2 de la Constitución Española:"Las normas relativas a los derechos fundamentales y a las libertades que la Constitución reconoce se interpretarán de conformidad con la Declaración Universal de Derechos Humanos y los tratados y acuerdos internacionales sobre las mismas ratificadas por España"; o bien mediante un tratamiento separado para los tratados de de derechos humanos, otorgándoles por vía interpretativa valor supraconstitucional en Costa Rica; Constitucional en el caso de la Argentina y Colombia; o, también por vía interpretativa, jerarquía supralegal o legal como en el caso de Bolivia, Perú 
invocado como parámetro de constitucionalidad ${ }^{6}$. En otros casos, se ha dado inicio a un debate respecto a la jerarquía que ocupan los tratados de derechos humanos en el ámbito interno, como ocurre en el caso chileno.

Analizaremos enseguida la progresividad como principal carácter del DIDH. Para estos efectos seguiremos la obra del jurista venezolano Pedro Nikken, que dio visibilidad a esta temática con la obra que publicó en $1987^{7}$, y que desarrolla el sentido y alcance de la progresividad. Cerraremos la mirada a esta cuestión con algunos comentarios a sentencias de la Corte IDH donde se aprecia el impacto de este carácter en los criterios jurisprudenciales que aplica.

\section{Definición y CaRaCteres del DeRecho InTERnaCional De los Derechos Humanos}

El Derecho Internacional de los Derechos Humanos puede ser definido como un "Sistema de principios y normas que regula un sector de las relaciones de cooperación institucionalizada entre el Estado de desigual desarrollo socioeconómico y poder, cuyo objeto es el fomento del respeto a los derechos bumanos y libertades fundamentales universalmente reconocidos, así como el establecimiento de mecanismos para la garantía y protección de tales derechos y libertades, los cuales se califican de preocupación legítima y, en algunos casos, de intereses fundamentales para la actual comunidad internacional en su conjunto" 8 .

y Chile aunque con importantes debates en la doctrina que no han logrado definir el asunto incluso después de la Sentencia del Tribunal Constitucional chileno sobre responsabilidad penal juvenil o de menores infractores (junio de 2007).

6 Es el caso de Costa Rica: La posición asumida por la Sala Constitucional se inicia en 1990 y básicamente reconoce la supraconstitucionalidad de los derechos humanos. Este desarrollo ha tenido un fuerte impulso por la Sala Constitucional, que ha dicho "los tratados y en general, los instrumentos internacionales sobre derechos humanos tienen rango superior a la de los demás, y que tienen otra característica adicional -la más importante- que complementan la Constitución Política en su parte dogmática". Armijo, Gilbert (2003) "La Tutela Supraconstitucional de los Derechos Humanos en Costa Rica". Ius et Praxis. Vol. $9 \mathrm{~N}^{\circ} 1$, pp. 39-62.

Argentina: A partir de la reforma Constitucional de 1994 en la Argentina, junto con el reconocimiento de nuevos derechos y garantías a través del art. 75 inc. 22 se incorporaron con jerarquía Constitucional diez Tratados sobre Derechos Humanos: Declaración Americana de los Derechos y Deberes del Hombre; Declaración Universal de Derechos Humanos; Convención Americana sobre Derechos Humanos; Pacto Internacional de Derechos Económicos, Sociales y Culturales; Pacto Internacional de Derechos Civiles y Políticos y su Protocolo Facultativo; Convención sobre la Prevención y la Sanción del Delito de Genocidio; Convención Internacional sobre la Eliminación de todas las Formas de Discriminación Racial; Convención sobre la Eliminación de todas las Formas de Discriminación contra la Mujer; Convención contra la Tortura y otros Tratos o Penas Crueles, Inhumanos o Degradantes; Convención sobre los Derechos del Niño. Artículo 75 inc. 22 Constitución de la Nación Argentina.

7 Nikken, Pedro (1987) La Protección Internacional de los Derechos Humanos, su Desarrollo Progresivo. Madrid: Civitas.

s Villán Durán, Carlos (2002) Curso de Derecho internacional de los derechos bumanos. Madrid: Trotta, p. 85. 
En cuanto a su fundamento, la doctrina está de acuerdo en que reside en la dignidad de la persona humana ${ }^{9}$. Para los ius naturalistas, los derechos humanos se fundamentarán en la existencia de un orden natural superior al hombre, que se identifica con determinadas creencias religiosas. Para los positivistas, su fundamento residirá en las normas jurídicas vigentes que les reconocen.

Entre sus principales características existen algunas comunes con el DI, en tanto regula las relaciones entre Estados y las relaciones entre Estados y la Comunidad Internacional en su conjunto, y otras que le son particulares. Según Carlos Villán Durán ${ }^{10}$, el DIDH es: a) ideológico, ya que se fundamenta en la "superioridad de los valores que son inherentes a la persona humana"; b) derivado, ya que su fuente primera se encuentra en el derecho interno que al mismo tiempo juega un papel unificador respecto a las legislaciones nacionales; c) mínimo, en cuanto lo que se expresa en los tratados es un estándar básico, siempre susceptible de ampliación, aunque no de restricción ${ }^{11}$; d) objetivo, en tanto ampara derechos fundamentales de la persona; e) en materia de aplicación de normas, "la violación de una norma imperativa de derechos bumanos por parte de un Estado (ya sea norma de ius cogens o una norma convencional que le sea oponible) acarrea la obligación por parte del Estado de restablecer la situación jurídica infringida, indemnizar a la víctima o sus causababientes por los daños ocasionados, modificar la legislación o práctica administrativa interna bajo cuyo amparo se cometió la violación, así como investigar, perseguir y sancionar a los responsables de la violación..." 12 ; f) universal, lo que desde la perspectiva jurídica, está estrechamente relacionado con la imperatividad de los mismos, en dos casos: primero respecto de las normas imperativas o principios estructurales del ordenamiento (ius cogens) y en segundo lugar, respecto de aquellos derechos que regulados en origen por el derecho positivo, son aceptados voluntariamente por los Estados, en este caso su obligatoriedad se limita a los Estados que hayan aceptado la norma de derecho positivo y no a los restantes Estados. Otra parte de la doctrina,

Para Bobbio el problema reside en la protección y no en su fundamento, y para resolver la pregunta, sitúa en la Declaración Universal de los Derechos del Hombre, ratificada por la mayoría de los Estados en el mundo, la respuesta. Insiste, el problema no radica en el reconocimiento y la defensa teórica de los derechos, sino en su efectivo cumplimiento. "El problema grave de nuestro tiempo respecto a los derechos humanos no [es] el de fundamentarlos, sino el de protegerlos". Bоввıо, Norberto (1991) El Tiempo de los Derechos. Madrid: Sistema, p. 63.

10 BobBio (1991) 105.

II En el mismo sentido se refiere J. A. Carrillo Salcedo respecto al Convenio Europeo de Derechos Humanos: "los derechos reconocidos en el Convenio Europeo de Derechos Humanos se configuran como mínimo ya que, de conformidad a lo establecido en el artículo 53, ninguna de sus disposiciones debe ser interpretada en el sentido de limitar o perjudicar los derechos humanos y las libertades fundamentales que pudieran estar reconocidos en el ordenamiento jurídico interno de un estado parte, o en cualquier otro tratado de derechos humanos en el que este fuese igualmente parte". CARrillo Salcedo, Juan Antonio (2003) El Convenio Europeo de Derechos Humanos. Madrid: Tecnos, p. 24. 
agrega a estas características: e) la heterogeneidad de sus normas y f) su carácter evolutivo y dinámico ${ }^{13}$.

Gregorio Peces Barba sostiene, además, que existe un conjunto de principios de alcance erga omnes, independiente incluso, del principio del consentimiento de los Estados, lo que ha "introducido un cierto objetivismo en un estándar de alcance universal, que reconoce un mínimo de derechos a todas las personas, con independencia de la situación jurídica subjetiva del Estado de que se trate"14.

De los caracteres enumerados, nuestro trabajo se centrará en la progresividad.

\section{El CARÁCTER PROGRESIVO}

La progresividad es reconocida en diversos contextos ${ }^{15}$. Pedro Nikken, ex presidente de la Corte Interamericana, atribuye a la fundación de Naciones Unidas, la Organización de Estados Americanos y el Consejo de Europa, la instauración de verdaderos sistemas internacionales de protección a los derechos humanos, pues se trata de organizaciones sustentadas en tratados que, aunque de contenido diverso, crean al mismo tiempo órganos de carácter heterogéneo para el cumplimiento de los fines previstos, lo que identifica como una "suerte de fenómeno progresivo" 16 , en

Fernández de Casadevante Romani, Carlos (2003) Derecho Internacional de los Derechos Humanos. Madrid: Dilex, p. 62.

14 Peces Barba, Gregorio; Llamas Cascón, A; Fernández Liesa, C. (2001) Textos Básicos de Derechos Humanos, con estudios generales y especiales y comentarios a cada texto nacional e internacional. Pamplona: Aranzadi, p. 268.

15 La progresividad es mencionada por Carlos Fernández de Casadevante Romani, cuando constata el fortalecimiento del DIDH en dos sentidos: la progresiva aceptación de las técnicas de control por parte de los Estados, que se expresa en la aceptación de competencias de diversos órganos internacionales, y la progresiva elaboración de tratados que amparan derechos específicos contra posibles violaciones a los derechos humanos, ambas cuestiones, considera el autor, constituyen el carácter evolutivo y dinámico del DIDH. FERNÁNDEZ DE CASAdEvanTE ROMANI (2003) 62.

El carácter evolutivo y dinámico es analizado por J. A. Carrillo Salcedo desde la perspectiva de los criterios de interpretación aplicados por el Tribunal de Estrasburgo, el que ha manifestado una tendencia favorable a la protección de los derechos y libertades a través de una interpretación evolutiva y dinámica del Convenio Europeo: "Para el Tribunal, en efecto, el Convenio 'desborda el ámbito de la mera reciprocidad entre los Estados contratantes' porque, además de una red de compromisos sinalagmáticos bilaterales, "crea unas obligaciones objetivas que disfrutan de garantía colectiva", por lo que tiene carácter singular. Esta concepción de la naturaleza del Convenio, en la que se pone especial énfasis en su dimensión constitucional en tanto instrumento jurídico internacional que expresa un orden público europeo de los derechos humanos y libertades fundamentales, justifica que el Tribunal haya procedido a una interpretación evolutiva del Convenio, adaptada a las cambiantes condiciones de vida y no a las existentes en el momento de su adopción en 1950, y mediante la que ha ampliado el alcance de la responsabilidad internacional de los Estados parte". Carrillo Salcedo (2003) 94.

16 La progresividad es también tratada como un "proceso de codificación y desarrollo progresivo del derecho internacional como resultado de la Declaración Universal de los Derechos Humanos 
tanto se trata de un régimen de protección que "tiende a expandir su ámbito de modo continuado e irreversible, tanto en lo que se refiere al número y contenido de los derechos protegidos, como en lo que toca a la eficacia y el vigor de los procedimientos en virtud de los cuales órganos de la comunidad internacional pueden afirmar y salvaguardar su vigencia" 17 .

Hace 20 años no se concebía aún al Derecho Internacional de los Derechos Humanos como una rama dentro del Derecho Internacional, entonces, se hablaba de un "sistema internacional de protección de los derechos humanos"; es decir, en algunos años, la regulación internacional de los derechos humanos ha dado paso a una disciplina específica en el ámbito del DI. El estudio, entrega herramientas para comprender el rol que juega la progresividad en su configuración, que el autor considera inherente a la naturaleza misma del régimen.

Abordaremos su estudio desde dos ámbitos:

1) la concepción progresiva y

2) la progresividad operativa

\section{La concepción progresiva}

Se expresa en la evolución de los instrumentos jurídicos de protección a los derechos humanos desde las Declaraciones hacia los Tratados, de mayor efecto vinculante y, por tanto, de mayor exigibilidad. Entre las Declaraciones más importantes figuran: la Declaración Universal de Derechos Humanos (1948); la Declaración Americana sobre Derechos del Hombre (1948); la Declaración sobre Derechos y Deberes del Niño (1959); la Declaración sobre la Concesión de Independencia a los Países y Pueblos coloniales (1960); la Declaración de Naciones Unidas sobre Eliminación de Todas las Formas de Discriminación Racial (1963); la Declaración sobre Eliminación de Todas las Formas de Discriminación Contra la Mujer (1967).

Dentro del ordenamiento jurídico internacional, se verifica que las Declaraciones sobre derechos humanos han sido precursoras del establecimiento de mecanismos más vigorosos de protección, tanto en el ámbito regional como universal. A continuación, los tratados paulatinamente irán contemplando mayores mecanismos y órganos encargados de velar por el respeto a los derechos humanos en el ámbito internacional. Destacan, entre los primeros tratados: la Convención Europea sobre Derechos Humanos -que además de consagrar un régimen internacional de protección

y otros avances jurídico-políticos cuyos precedentes determinan el posterior reconocimiento universal de los derechos, complementado por un proceso de regionalización y de especificación...,. PECES BARBA (2001) 268.

NIKKEN (1987) 18. 
a los derechos humanos y libertades fundamentales es pieza angular en el proceso de integración europeo-; los pactos de Naciones Unidas: (Pacto sobre Derechos Civiles y Políticos y Pacto relativo a los Derechos Económicos, Sociales y Culturales) y en el sistema interamericano la Convención Interamericana de Derechos Humanos.

Dicho lo anterior, a partir de la fundación de Naciones Unidas, se han adoptado sucesivamente numerosos y multitemáticos instrumentos internacionales, que aunque con distinto alcance y dispar fuerza vinculante, constituyen hoy en día parte del denominado Derecho Internacional de los Derechos Humanos, y expresan su carácter evolutivo y progresivo.

Entre las instituciones y organismos creados en el ámbito del Derecho Internacional destacan, entre otros: el Consejo Económico y Social; el Comité de Derechos Humanos ${ }^{18}$; el Alto Comisionado de las Naciones Unidas para los Refugiados; el Comité Especial contra el Apartheid, el Comité contra la Tortura; el Comité de Derechos Económicos Sociales y Culturales; el Comité de los Derechos del Niño y el Consejo de Derechos Humanos de Naciones Unidas. Y en cuanto al control jurisdiccional se crean, en el ámbito de la responsabilidad de los estados: la Corte Europea de Derechos Humanos (1950), la Corte Interamericana de Derechos Humanos (1969), y en el ámbito de la responsabilidad penal internacional: el Tribunal Penal Internacional para la ex Yugoslavia (1993), el Tribunal Penal Internacional para Ruanda (1994), y la Corte Penal Internacional (1998).

Las bases de la progresividad se encuentran en la propia naturaleza de los regímenes internacionales de protección, porque así lo han declarado los Estados signatarios de los instrumentos internacionales y se han creado los "dispositivos" adecuados para que las garantías, establecidas como un mínimo en su origen, puedan "extenderse a nuevos ámbitos". Ello se debe muy particularmente a los mecanismos de interpretación, evolutiva y humanitaria, que permiten un campo amplio a los órganos encargados de su aplicación ${ }^{19}$.

18 "Con el Comité de Derechos Humanos como pionero y especialmente tras el fin de la guerra fría, tanto este como otros comités han ampliado, mediante la revisión de sus reglamentos y métodos de trabajo, su propia capacidad de actuación. De este modo han asumido funciones nuevas, como la elaboración de observaciones finales a cada país, que constituyen, dentro del marco del examen de informes, una evaluación sobre la situación de los derechos humanos en cada Estado". Peces Barba (2001) 290.

19 En relación a los criterios de interpretación del Convenio Europeo de Derechos Humanos aplicados por la Corte de Estrasburgo, J. A. Carrillo Salcedo dice que en tanto tratado de protección de derechos bumanos y libertades fundamentales sus normas de interpretación escapan a las reglas generales de interpretación en materia de tratados y que responden a la naturaleza específica del Convenio, el autor describe dos tendencias "por una parte, la que favorece a la soberanía de los Estados, que se expresa en una posición de autocontrol por parte del Tribunal respecto del alcance de su jurisdicción; por otra; una tendencia más progresiva, de activismo judicial, favorecedora de la protección de derechos y libertades y que tiende por ello a restringir el ámbito de competencias de los Estados parte". CARrilo Salcedo (2003) 90. 
De la misma forma, el carácter progresivo se encuentra en la conceptualización de numerosos derechos cuyos tratados expresamente establecen que se trata de nociones abiertas a futuras ampliaciones, en cuanto a su significado y alcance ${ }^{20}$. Asimismo, existe un tercer ámbito de la concepción progresiva que proviene de la jurisprudencia desarrollada por los tribunales internacionales de derechos humanos y que determina el incremento de su estándar de protección, como veremos más adelante.

\section{La progresividad operativa}

Se observa en "la práctica de las organizaciones internacionales y de las instituciones de protección a los derechos humanos. Esa práctica ba servido en muchas ocasiones para despejar dudas teóricas sobre el sentido de algunas disposiciones convencionales, o para impulsar una evolución hacia grados más elevados de protección, o para dar un sentido renovado a los procedimientos -si no a crearlos-, con el objeto de perfeccionar mecanismos preexistentes" 21 .

En el ámbito de la progresividad operativa, destacan dos aspectos desarrollados por la doctrina internacionalista: a) el derecho individual de queja, demanda o petición; y b) los procedimientos que determinan la posición del Estado demandado en casos de violaciones a los derechos humanos.

a).- En cuanto a la iniciativa individual, ella ha sido planteada por el Juez de la Corte Interamericana, Antonio Cançado Trindade, como "una conquista definitiva del Derecho Internacional de los Derechos Humanos", ya que forma parte de la esencia de la protección internacional, por situar al individuo frente al Estado en los supuestos de que se haya producido una violación de los derechos humanos e implica simplemente "dotarlo de una capacidad procesal internacional" 22 . Tres siglos de un ordenamiento internacional definido por la relación entre Estados soberanos y la exclusión del

20 En este sentido, sobre la Convención de Naciones Unidas contra la Tortura (1984), Carlos Villán señala que si bien se ha dado un carácter restrictivo a la definición de tortura contenida en el art. 1, en el art. 1.2 se amplía el alcance a cualquier instrumento nacional o internacional que pueda contener mayores estándares de protección, lo que a juicio del autor, permitió su posterior extensión. Al respecto señala: "Más bien, la CCT codificó por primera vez en un tratado internacional de alcance universal el concepto tradicional de tortura y otros tratos, aunque se le añadieron algunos aspectos de desarrollo progresivo que, como veremos, no son desdeñables, pues constituyen en 1984 la "norma mínima" comúnmente aceptada, a partir de la cual han sido posibles otros desarrollos, tanto legislativos (nacionales e internacionales) como jurisprudenciales...". Villán Durán, Carlos (2004) "La Práctica de la Tortura y los Malos Tratos en el Mundo". En VV.AA. Jornadas sobre derechos bumanos, XXII Cursos de Verano en San Sebastián, Edición Ararteko, p. 46. NIKKEN (1987) 166.

22 Cançado Trindade, Antônio (2001) El acceso directo del individuo a los Tribunales Internacionales de derechos bumanos. Bilbao: Universidad de Deusto, p. 29. 
individuo como sujeto de derecho internacional demostraron que este esquema de relaciones era insuficiente para evitar y sancionar las violaciones a los derechos humanos. El Juez Cançado señala que las atroces violaciones a los derechos humanos, "despertaron la conciencia jurídica universal para la necesidad de reconceptualizar las bases del ordenamiento internacional restituyendo al ser bumano la posición central de donde habia sido desplazado. Esta reconstrucción, sobre bases humanas, tomó por fundamento conceptual, cánones enteramente distintos, como lo son los de la realización de valores comunes superiores, de la titularidad de derechos del propio ser humano, de la garantía colectiva de su realización, y del carácter objetivo de las obligaciones de protección. El orden internacional de las soberanías cedía terreno al de la solidaridad"23.

Con la fundación de las Naciones Unidas se dio inicio la adopción de un sistema que admite la petición individual en diversos tratados y que es especialmente relevante en los sistemas regionales de protección (europeo e interamericano). El derecho de petición individual ha trascendido el escenario de la reparación individual, ya que el derecho de petición permite, asimismo, asegurar el mayor respeto a los derechos humanos, ocasionando incluso transformaciones en el derecho interno y en la propia práctica de los órganos estatales.

La mayoría de los tratados que contemplan el derecho de petición individual exigen que el peticionario tenga o pretenda tener el carácter de víctima de una violación a los derechos humanos, pero incluso en este sentido, los tribunales internacionales de derechos humanos han ampliado la noción de víctima para abarcar tanto a las víctimas directas como indirectas, e incluso a las víctimas potenciales. Tanto la Convención Americana sobre Derechos Humanos, como la Carta Africana de Derechos Humanos y de los Pueblos adoptan una solución "más liberal", ya que no imponen como requisito que el peticionario tenga la condición de víctima ${ }^{24}$.

CANÇAdo Trindade, Antônio (2001) 30.

24 Convención Americana de Derechos Humanos, artículo 44: "Cualquier persona o grupo de personas, o entidad no gubernamental legalmente reconocida en uno o más Estados miembros de la Organización, puede presentar a la Comisión peticiones que contengan denuncias o quejas de violación de esta Convención por un Estado Parte".

Carta Africana sobre los Derechos Humanos y de los Pueblos, artículo 56: "Los comunicados relativos a los derechos humanos y de los pueblos a los que se hace referencia en el artículo 55 recibidos por la Comisión serán considerados si:

sus autores se identifican, aunque soliciten el anonimato;

son compatibles con la Carta de la Organización para la Unidad Africana o con la presente carta;

no están escritos en un lenguaje despectivo o insultante dirigido contra el Estado implicado, sus instituciones o contra la Organización para la Unidad Africana;

no están basados exclusivamente en noticias difundidas por los medios de comunicación:

son enviados después de agotar los recursos locales, si es que existen, a no ser que resulte obvio que tal proceso sería demasiado largo;

son presentados dentro de un período de tiempo razonable a partir del momento en que se agotaron los recursos locales o de la fecha en que la Comisión es puesta al corriente del asunto y; 
Sobre la materia, la práctica jurisprudencial del los tribunales internacionales ha adoptado siempre un criterio favorable a "una protección más eficaz de las supuestas víctimas".

b).- Procedimientos que determinan la posición del Estado en demandas por violaciones a los derechos humanos: en este ámbito también se ha verificado un desarrollo progresivo que se expresa en la flexibilización de los requisitos para la iniciativa procesal en lo que se refiere al agotamiento de los recursos internos, lo que facilita el acceso a la jurisdicción internacional, y también se han observado progresos en cuanto a la iniciativa procesal para el conocimiento de eventuales violaciones a los derechos humanos que se admiten tanto a petición de una parte, como también pueden emprenderse de oficio (artículo 26.2 del Reglamento de la Comisión Interamericana de Derechos Humanos).

En cuanto a la posición del Estado demandado y su deber de aportar pruebas y cooperar con la investigación de denuncias, los avances en este campo han permitido enfrentar una de las mayores dificultades del proceso contradictorio: la falta de cooperación de los Estados para aportar elementos probatorios. La práctica habitual de no cooperación impulsó a que la Comisión Interamericana, mediante una enmienda a su Reglamento, otorgara efectos al silencio de los Estados: "Se presumirán verdaderos los bechos alegados en la petición cuyas partes pertinentes hayan sido transmitidas al Estado en cuestión, si este no suministra información relevante para controvertirlos dentro del plazo fijado por la Comisión conforme al artículo 38 del presente Reglamento, siempre que de otros elementos de convicción no resultare una conclusión contraria" 25 .

Por la trascendencia de la disposición, la Corte Interamericana ha sido cautelosa en su aplicación y ha hecho una interpretación flexible del criterio, ya que su consecuencia inmediata es que la carga de la prueba se traslada de quien afirma el hecho a quien lo niega, en este caso al Estado.

\section{La Progresividad en la jurisprudencia de la Corte IDH}

El tratamiento de la progresividad en la jurisprudencia de la Corte ha incidido en distintos ámbitos de su actividad. En ocasiones, ha sido el fundamento para la calificación de actos que en el pasado consideró crueles e inhumanos, y que posteriormente serán calificados como tortura. También ha permitido la construcción de criterios específicos en relación a la carga de la prueba en casos de desaparición forzada, o la construcción de

no tratan casos que ya han sido solucionados por los Estados implicados de conformidad con los principios de la Carta de Naciones Unidas, la Carta de la Organización para la Unidad Africana o las disposiciones de la presente Carta." 
estructuras jurídicas para sostener la posición de garante en que se encuentra el Estado frente a personas privadas de libertad, todas ellas cuestiones que la Corte ha sostenido pacíficamente en el ámbito interamericano y que constituyen hoy criterios validados y reiterados en su jurisprudencia, como veremos a continuación.

\section{Noción de tortura}

En el "Caso Cantoral Benavides" del año 200026, la Corte manifestó su reconocimiento a la necesaria "protección progresiva de los derechos bumanos" y, a diferencia de lo que sostuvo en el caso Loayza Tamayo vs. Perú cuyos hechos calificó como tratos crueles e inhumanos, consideró que la víctima fue sometida a tortura. La mayor calificación, responde a "las crecientes exigencias de protección de los derechos y de las libertades fundamentales" a la que "debe corresponder una mayor firmeza al enfrentar las infracciones a los valores básicos de las sociedades democráticas" 27.

La Corte recuerda lo que ha dicho el $\mathrm{TEDH}^{28}$, que ciertos actos que en el pasado fueron calificados como tratos inhumanos, pueden ser calificados en el futuro como tortura, ello por la necesidad de una protección progresiva a los derechos humanos y la exigencia de una mayor "firmeza" para censurar las violaciones, ya que la integridad personal y la dignidad del hombre son valores fundamentales en las sociedades democráticas.

La sentencia, asimismo, aborda la hipótesis de la tortura psicológica, contenida en la normativa internacional, también planteada por la jurisprudencia del Tribunal Europeo de Derechos Humanos ${ }^{29}$. La Corte señala que según las normas internacionales de protección, no solo la violencia física, sino también aquella que produce un sufrimiento psíquico, o moral agudo ${ }^{30}$, puede ser considerada como tortura. Recuerda lo que ha dicho la Corte Europea: "es suficiente el mero peligro de que vaya a cometerse alguna de

26 Según la demanda, la víctima habría sido privada ilegalmente de su libertad, encarcelada y sometida a tratos crueles inhumanos y degradantes.

La Comisión solicitó a la Corte que esta decidiera si el Estado de Perú violó los artículos 1.1 (Obligación de Respetar Derechos), 2 (Deber de Adoptar Disposiciones de Derecho Interno), 7.1 a 7.6 (Derecho a la Libertad Personal), 5 (Derecho a la Integridad Personal), 8 (Garantías Judiciales), 25 (Protección Judicial), de la Convención Interamericana y los artículos 2 y 8 de la Convención Interamericana para Prevenir y Sancionar la Tortura. Corte IDH. Caso Cantoral Benavides vs. Perú. Serie $\mathrm{C} \mathrm{N}^{\circ} 69$ Sentencia de 18 de agosto de 2000 .

27 CIDH (2000) Caso Cantoral Benavides, párrafo 99.

28 Eur. Court HR, Selmouni v. France, supra nota 51, para. 101.

29 En adelante TEDH o Corte Europea.

30 "Merece destacarse que según las normas internacionales de protección, la tortura no solamente puede perpetrada mediante ejercicio de la violencia física, sino también a través de actos que produzcan en la víctima un sufrimiento físico o moral agudo. CIDH (2000) Caso Cantoral Benavides, párrafo 100. 
las conductas del artículo 3 de la Convención Europea para que pueda considerarse infringida la mencionada disposición, aunque el riesgo de que se trata debe ser real e inmediato. En concordancia amenazar a alguien con torturarle puede constituir, en determinadas circunstancias, por 10 menos "un trato inbumano" ${ }^{31}$. Asimismo, la Corte se refiere al Comité de Derechos Humanos de Naciones Unidas, que ha calificado "la amenaza de hacer sufrir a una persona una grave lesión física como una tortura psicológica"32.

Desde el criterio de la necesidad de una protección progresiva, la Corte argumentará su cambio de criterio, bajando el umbral del dolor para los actos que considera tortura, haciendo operativo lo que ya declaró en el caso Loayza Tamayo: el análisis de la violación caso a caso.

\section{Deber de aportar pruebas}

La prueba de las violaciones a los derechos humanos, ha supuesto enormes dificultades en el campo de la justicia en América Latina. La mayoría de las graves y masivas violaciones a los derechos humanos fueron concebidas y ejecutadas de manera clandestina, procurando eliminar cualquier vestigio de su ocurrencia.

Para el Derecho Internacional el silencio del Estado no tiene una lectura unívoca. Sin embargo, en los casos que se investigan violaciones a los derechos humanos parece claro que el silencio del Estado no puede llegar a convertirse en un obstáculo para la investigación que, en definitiva, frustre la protección internacional, haciendo inoperante un sistema internacional de protección a los derechos humanos.

Una enmienda al Reglamento de la Comisión Interamericana de 1967 , incorporó por primera vez una disposición al artículo 42 -posteriormente modificado-, actualmente tratado en el artículo 39, que prevé una solución a este silencio, como ya lo señalamos. Creemos pertinente mencionar la primera sentencia de la Corte, el Caso Velásquez Rodríguez de 1988 por la desaparición forzada del estudiante Manfredo Velásquez Rodríguez. En la sentencia, la Corte previene que antes del examen de las pruebas, debe "precisar" ciertas cuestiones. Se refiere a la "carga de la prueba" y "criterios generales que orientan su valoración y la determinación de los hechos probados".

La Corte señaló que en los casos por violaciones a los derechos humanos "la defensa del Estado no puede descansar sobre la imposibilidad del demandante de allegar pruebas que, en muchos casos, no pueden obtenerse sin la cooperación del Estado. Es el Estado quien tiene el control de los medios para aclarar bechos ocurridos dentro de su territorio. La Comisión, aunque tiene facultades 
para realizar investigaciones, en la práctica depende, para poder efectuarlas dentro de la jurisdicción del Estado, de la cooperación y de los medios que le propone el Gobierno"33. En este sentido, el Comité de Derechos Humanos de las Naciones Unidas ha señalado que "la carga de la prueba no puede recaer únicamente en el autor de la Comunicación, considerando en particular que el autor y el Estado Parte no siempre tienen acceso igual a las pruebas y que frecuentemente solo el Estado Parte tiene acceso a la información pertinente... En los casos que los autores hayan presentado al Comité cargos apoyados por pruebas testificales... y en que las declaraciones ulteriores del caso dependan de la información que está exclusivamente en manos del Estado Parte, el Comité podrá considerar que los cargos son justificados a menos que el Estado Parte presente, pruebas satisfactorias y explicaciones en sentido contrario" 34 .

En cuanto a los criterios de valoración, recuerda que la materia no ha sido tratada en el Estatuto de la Corte ni en su Reglamento. "Sin embargo, la jurisprudencia internacional ha sostenido la potestad de los tribunales para evaluar libremente las pruebas, aunque ba evitado siempre suministrar una rígida determinación del quantum de prueba necesario para fundar el fallo..."35.

El Caso Cantoral Benavides amplía lo señalado el caso anterior: "las partes deben allegar al Tribunal toda prueba requerida por éste, sea documental, testimonial, pericial o de otra índole. Los Estados no pueden alegar razones de orden interno para dejar de cumplir con los requerimientos de esta Corte, como sucede en este caso..." 36 y continúa, "Las partes, y en particular el Estado, deben facilitar al Tribunal todos los elementos probatorios requeridos - de oficio, como prueba para mejor resolver o a petición de parte- a fin de que éste tenga el mayor número de elementos de juicio para valorar y lograr conclusiones sólidas sobre los hechos. En los procesos sobre violaciones de derechos bumanos suele ocurrir que el demandante esté imposibilitado para allegar pruebas, puesto que éstas, en muchos casos, no pueden obtenerse sin la cooperación del Estado, que tiene el control de los medios de necesarios para aclarar los bechos ocurridos dentro de su territorio" 37 .

La inversión de la carga de la prueba ha supuesto el desarrollo de criterios propios para la investigación de las violaciones a los derechos humanos por los tribunales internacionales de derechos humanos y, analizada en conjunto con otros criterios relevantes, ha permitido acreditar hechos que difícilmente podrían haberse probado si se aplicaran los principios concebidos en el ámbito del derecho interno. Es importante recordar que

CIDH (1988) Caso Velásquez Rodríguez vs. Honduras. Serie C No 4 . Sentencia de 29 de julio de 1988, párrafo 135-136. viembre de 2000, párrafo 152-153.

35 CIDH (2000) Caso Bámaca Velásquez, párrafo 127.

36 CIDH (2000) Caso Cantoral Benavides, párrafo 54.

$37 \mathrm{CIDH}$ (2000) Caso Cantoral Benavides, párrafo 55. 
la naturaleza de la jurisdicción ejercida por la Corte persigue el establecimiento de la responsabilidad estatal y no personal, jurisdicción que tal y como hemos analizado, ha desarrollado reglas específicas que no pueden ser examinadas desde la lógica del derecho interno.

\section{Posición de garante del Estado respecto a personas privadas de libertad}

Nos referimos a una obligación activa que la Corte construye sobre la base del conjunto de obligaciones contenidas en los instrumentos internacionales, que, si bien no es mencionada de forma expresa en los instrumentos internacionales, tampoco ha sido controvertida en el ámbito interamericano.

En el caso Cantoral Benavides vs. Perú, la Corte manifestó que "toda persona privada de libertad tiene derecho a vivir en condiciones de detención compatibles con su dignidad personal y el Estado debe garantizarle el derecho a la vida $y$ a la integridad personal. En consecuencia, el Estado como responsable de los establecimientos de detención es el garante de estos derechos de los detenidos" 38 .

En el caso Instituto de Reeducación del Menor vs. Paraguay, la Corte desarrolla la responsabilidad del Estado como garante de los derechos de las personas privadas de libertad: "Frente a las personas privadas de libertad, el Estado se encuentra en una posición especial de garante, toda vez que las autoridades penitenciarias ejercen un fuerte control o dominio sobre las personas que se encuentran sujetas a su custodia. De este modo, se produce una relación e interacción especial de sujeción entre la persona privada de libertad y el Estado, caracterizada por particular intensidad con que el Estado puede regular sus derechos y obligaciones y por las circunstancias propias del encierro, en donde al recluso se le impide satisfacer por cuenta propia una serie de necesidades básicas que son esenciales para el desarrollo de una vida digna"39. La Corte considera que en consecuencia, le corresponde al Estado "asumir" un conjunto de obligaciones y emprender diversas "iniciativas" para garantizar el derecho de los reclusos a "condiciones necesarias para desarrollar una vida digna y contribuir al goce efectivo de aquellos derechos que bajo ninguna circunstancia pueden restringirse o de aquellos cuya restricción no deriva necesariamente de la privación de libertad y que, por tanto, no es permisible. De no ser así, ello implicaría que la privación de libertad despoja a la persona de su titularidad respecto de todos los derechos humanos, lo que no es posible aceptar" 40 . En este caso, por tratarse de actos que vulneran derechos de los niños, la Corte añade que en estos casos el Estado tiene "una obligación adicional", ya que le corresponde "asumir su posición especial de garante con 
mayor cuidado y responsabilidad, y debe tomar medidas especiales orientadas al principio del interés superior del niño" 41.

También se refiere a la posición de garante en el caso Tibi vs. Ecuador, donde la Corte tiene oportunidad de pronunciarse acerca del deber del Estado de proporcionar atención y tratamiento médico adecuados, llegando a considerar que, cuando esta atención es deficiente, se configura una violación al artículo 5 de la Convención Interamericana de Derechos Humanos. El caso Tibi cuenta además con el Voto Concurrente Razonado del Juez Sergio García Ramírez, que explica la noción del Estado garante: "En el Derecho penal, el garante del bien jurídico está llamado a responder del resultado lesivo que no impide, pudiendo y debiendo bacerlo, bajo la fórmula de la comisión por omisión. En la jurisprudencia de la Corte se ba manejado el concepto de garante con una caracterización que guarda cercanía conceptual con la que acogen los ordenamientos de aquella materia: por una parte, la existencia de una obligación que proviene de determinada fuente; por la otra, la presencia de un resultado lesivo típico, que se pone a la cuenta del obligado...Abora bien, esa obligación y la responsabilidad consecuente se extreman, adquieren una intensidad mucho más acentuada, son aún más exigibles, con todo lo que ello supone, cuando el sujeto titular de derechos queda a merced del Estado -por ejemplo, en una "institución total", donde todo se regula y supervisa-y no puede, por sí mismo, ejercitar sus derechos e impedir el asedio de quienes los vulneran... Si en la bipótesis penal de la comisión por omisión la posición de garante surge de la ley o del contrato, en el de la detención proviene de una situación de jure y otra de facto, derivada de aquella. Por una parte la inmensa restricción de libertad que existe en la detención procesal o en la prisión punitiva. Por la otra, la situación real que esta restricción engendra" 42. El Juez estima que la función de garante implica el deber de omitir todo aquello que lleve a someter al sujeto a privaciones más allá de las "estrictamente necesarias para efectos de prisión o cumplimiento de condena" y por la otra a "proveer" todo cuanto resulte necesario para "asegurar los fines de la reclusión: seguridad y readaptación social" 43.

\section{CONCLUSIONES}

La progresividad del DIDH imprime un signo positivo al avance del reconocimiento de los derechos humanos, a medida que se verifica su desarrollo, nuevas perspectivas se abren o profundizan. En la actualidad la jurisprudencia de los tribunales superiores nacionales dan cuentan de nuevos logros y perspectivas de esa progresividad. Pero tampoco queremos señalar

\footnotetext{
41 CIDH (2004) Caso Instituto Reeducación del Menor, párrafo 160.

42 CIDH (2004) Caso Tibi vs. Ecuador. Serie C N ${ }^{\circ} 114$. Sentencia de 7 de sepriembre de 2004. Voto Concurrente Razonado Juez Sergio García Ramírez, párrafos 14, 15, 17.

43 CIDH (2004) Caso Tibi vs. Ecuador, párrafo 18.
} 
con esta conclusión que la vigencia de los derechos humanos sean hoy algo consolidado en el ámbito interamericano, queremos poner el acento en que este proceso es evolutivo, de manera que cada año se verifican, y verificarán, mayores y mejores estándares de protección que enfrenten nuevos desafíos en el campo de los derechos humanos como ocurre con la protección de grupos vulnerables.

Entre los elementos sistematizados por Pedro Nikken, el rol de la persona como sujeto de derecho internacional a través del reconocimiento del derecho de petición es un asunto consolidado, pero sorprendente si estudiamos el desarrollo del derecho, esta cuestión ya no es discutible, ni en el ámbito europeo, ni en el africano ni tampoco en el latinoameriano.

La proliferación de instrumentos internacionales, desde las Declaraciones a las Convenciones y la paulatina creación de órganos encargados de su verificación y cumplimiento, es un avance positivo e innegable, aunque la crítica persista, es decir, la insuficiente fuerza obligatoria de los instrumentos y la falta de exigibilidad de las recomendaciones y observaciones emitidas por los órganos encargados de su vigilancia.

En el desarrollo jurisprudencial del tratamiento de la tortura y los otros tratos, la concepción progresiva del Derecho Internacional de los Derechos Humanos es uno de los elementos sobre el cual la Corte sustenta sus criterios. No en el sentido de crear nuevos derechos, sino en tanto que protege de mejor modo el derecho a la integridad personal, sin alterar el contenido esencial del derecho. En el trabajo jurisprudencial de la Corte Interamericana de Derechos Humanos, han sido decisivas las opiniones calificadas emitidas en el ámbito del Comité de Derechos Humanos y del Comité contra la Tortura y en el plano jurisdiccional: el Tribunal Internacional de Justicia, el Tribunal Europeo de Derechos Humanos, el Tribunal Especial para la antigua Yugoslavia, y el Tribunal Especial para Rwanda.

La obligación de aportar pruebas, que en el sistema interamericano se impone a los Estados demandados, ha venido a modificar en la práctica la carga de la prueba y ha permitido superar las dificultades probatorias, demasiado frecuentes en el plano de la investigación de las violaciones a los derechos humanos. La Corte ha dicho que la defensa de los Estados no puede sustentarse en la incapacidad de los demandantes de aportar pruebas, especialmente cuando es el Estado el que tiene el control de los medios probatorios.

La Corte advierte oportunamente la situación de potencial peligro que supone toda medida de detención arbitraria, que implica que junto con el derecho a la libertad personal, otros derechos pueden verse igualmente afectados. Lo mismo ocurre con la aplicación de medidas especiales en el marco de la aplicación de legislaciones antiterroristas, cuya aplicación en muchos países han supuesto graves violaciones a los derechos humanos. En el caso de las personas privadas de su libertad las obligaciones 
que corresponden al Estado, le convierten en un garante de que otros derechos fundamentales no se vean afectados por la privación de libertad.

El nuevo desafío para la Corte Interamericana y los actores a favor de los derechos humanos del continente es, ahora, definir y establecer los mecanismos que aseguren la recepción en el derecho interno de su doctrina, labor que debe ir acompañada de la voluntad real y efectiva de los Estados americanos para avanzar en un modelo de protección que, pese a todas sus imperfecciones, es hasta ahora el que con más decisión ha venido a amparar a las víctimas de las más graves violaciones a los derechos humanos ocurridas en nuestro continente.

\section{BiBLIOGRAFÍA}

- Armijo, Gilbert (2003). "La Tutela Supraconstitucional de los Derechos Humanos en Costa Rica". Ius et Praxis. Vol. $9 \mathrm{~N}^{\circ} 1$.

- Bobbio, Norberto (1991). El Tiempo de los Derechos. Madrid: Sistema.

- Cançado Trindade, Antônio (2001). El acceso directo del individuo a los Tribunales Internacionales de derechos humanos. Bilbao: Universidad de Deusto.

- Carrillo Salcedo, Juan Antonio (2003) El Convenio Europeo de Derechos Humanos. Madrid: Tecnos.

- Fernández de Casadevante Romani, Carlos (2003). Derecho Internacional de los Derechos Humanos. Madrid: Dilex.

- Nikken, Pedro (1987). La Protección Internacional de los Derechos Humanos, su Desarrollo Progresivo. Madrid: Civitas.

- Peces Barba, Gregorio; Llamas Cascón, A; Fernández Liesa, C. (2001) Textos Básicos de Derechos Humanos, con estudios generales y especiales y comentarios a cada texto nacional e internacional. Pamplona: Arazandi.

- Villán Durán, Carlos (2002) Curso de Derecho internacional de los derechos bumanos. Madrid: Trotta.

(2004) "La Práctica de la Tortura y los Malos Tratos en

el Mundo”. En VV.AA. Jornadas sobre derechos bumanos. San Sebastián: Ararteko.

\section{JURISPRUDENCIA}

- Incidente de inconstitucionalidad de los indultos dictados por el decreto 2741/1990 del Poder Ejecutivo Nacional. Cámara Nacional de Apelaciones en lo Criminal y Correccional Federal, en pleno. Dictada el 25 de abril de 2007.

- Corte Suprema de Chile, sentencia de 22 de agosto de 1996, $\mathrm{N}^{\circ}$ 2.277-96 por el homicidio de Carmelo Soria. 
- Corte IDH. Caso Velásquez Rodríguez vs. Honduras. Serie C $\mathrm{N}^{\circ} 4$. Sentencia de 29 de julio de 1988.

- Corte IDH. Caso Godínez Cruz. Serie C N N $^{\circ}$. Sentencia de 20 de enero de 1989

- Corte IDH. Caso Loayza Tamayo vs. Perú. Serie C No33 Sentencia de 17 de septiembre de 1997.

- Corte IDH. Caso Suárez Rosero vs. Ecuador. Serie C No 35 Sentencia de 12 de noviembre de 1997.

- Corte IDH. Caso "Castillo Petruzzi y otros vs. Perú", Serie C No 52. Sentencia de 30 de mayo de 1999.

- Corte IDH. Caso Bámaca Velásquez vs. Guatemala. Serie C No 70. Sentencia de 25 de noviembre de 2000.

- Corte IDH. Caso Cantoral Benavides vs. Perú. Serie C No 69 Sentencia de 18 de agosto de 2000. Reparaciones (art. 63.1 Convención Americana sobre Derechos Humanos). Serie C No 88 Sentencia de 3 de diciembre de 2001.

- Corte IDH. Caso "Instituto de Reeducación del Menor" vs. Paraguay. Serie C No 112 Sentencia de 2 de septiembre de 2004.

- Corte IDH. Caso Tibi vs. Ecuador. Serie C No 114. Sentencia de 7 de septiembre de 2004.

- Corte IDH. Caso Caesar vs. Trinidad y Tobago. Serie C No 123 . Sentencia 11 de marzo 2005.

- Corte IDH. Caso Gutiérrez Soler vs. Colombia. Serie C No 132. Sentencia de 12 de septiembre de 2005. 